\title{
Reconstruction of the Second Metacarpal Bone after Bone Tumor Resection with Free Fibular Graft
}

\author{
Hugo Fernandes ${ }^{1}$, Mariana Almeida ${ }^{1}$, Rita Lopes ${ }^{1}$, João Sousa ${ }^{1}$, Estevens Reis ${ }^{2}$, Leonor Fernandes ${ }^{1}$ \\ Department of Orthopedics, ${ }^{1}$ Centro Hospitalar do Oeste - Torres Vedras, Portugal; ${ }^{2}$ Clinica SOERAD - Torres Vedras, Portugal.
}

\section{Corresponding Author: \\ Dr. Hugo Fernandes \\ Email: h5caetano5@gmail.com}

This is an Open Access article distributed under the terms of the Creative Commons Attribution License (creativecommons.org/ licenses/by/3.0).

\begin{abstract}
Background: Bone giant cell tumors are rarely found on the hand. Several treatments have been described but only the resection/ amputation of the affected segment can offer an effective cure in advanced cases. Various forms of reconstruction have been described, namely using a free graft of fibula. Case Report: The authors present a case of a man with an osteolytic and expansive lesion of the distal end of the second metacarpal that was treated with resection and autologous free fibular graft with good clinical and radiologic outcome. Conclusion: Free fibular graft is a possible solution to avoid ray amputation in cases of bone tumors in the metacarpals.
\end{abstract}

Keywords: Bone Neoplasms, Bone Transplantation, Cartilage, Fibula, Metacarpal Bones.

\section{Introduction}

Bone giant cell tumors are usually benign but can be locally aggressive. The first time this tumor was described was in the early nineteenth century by Astley Cooper (1818) [1]. These tumors account for $4-5 \%$ of all primary bone tumors, upto $20 \%$ are benign and typically involve the meta-epiphyseal region of long bones [2,3]. They are rarely found on the hand, corresponding only to $1-4 \%$ of all hand bone tumors [3].

Several treatments have been described, but in more advanced stages only the resection/ amputation of the affected segment can offer an effective cure. This can lead to disability, more or less pronounced, depending on which bone is involved and the characteristics of the patient. Over the years, various forms of reconstruction have been described, but it is difficult to provide a return to the previous functional level $[4,5]$.

\section{Case Report}

A 37-year-old man, with no relevant medical or surgical pathology, a heavy factory worker, had a mass in the second metacarpal of the left hand. There had been progressive growth over at least four years, without accompanying symptoms and without functional impairment [Fig.1]. The patient did not present other masses of similar characteristics. An X-ray was performed and showed an osteolytic and expansive lesion of the distal end of the second metacarpal [Fig.2,3]. Resection and reconstruction with autologous free fibular graft was decided.

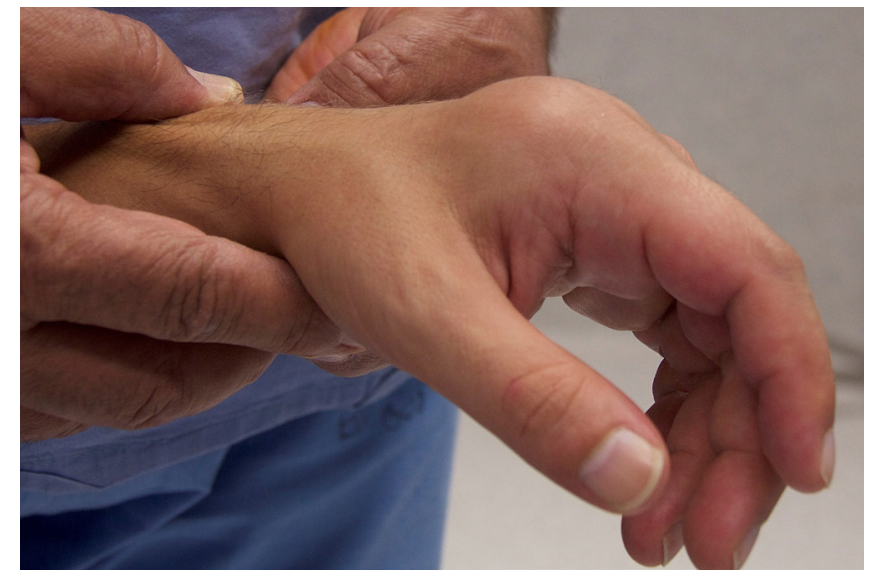

Fig.1: Swelling in the second metacarpal bone. 

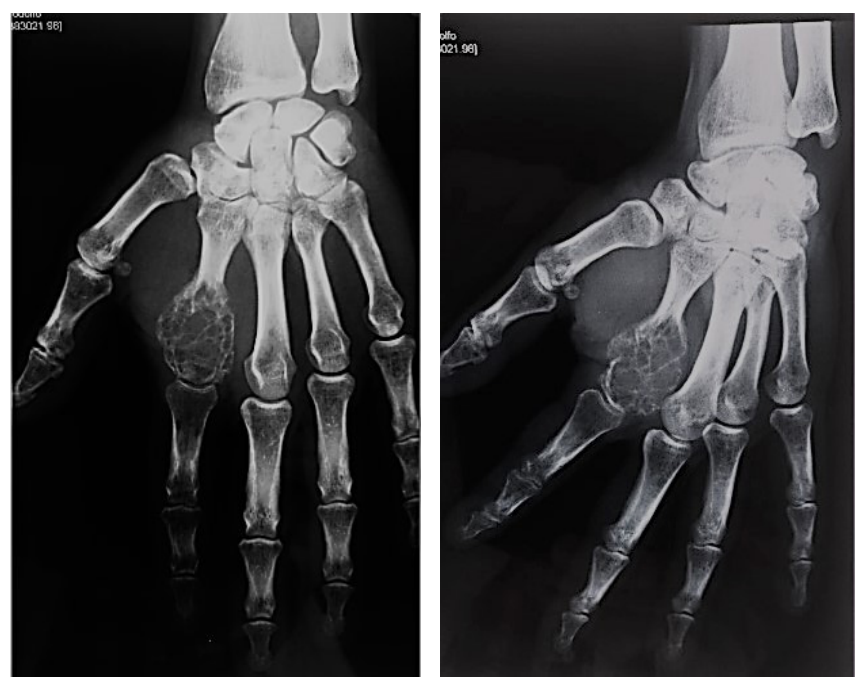

Fig.2,3: AP and lateral X-ray view showing osteolytic and expansive lesion of the distal end of the second metacarpal.

The patient underwent general anesthesia with a pneumatic tourniquet at the root of the upper limb and at the root of the lower limb. A dorsal direct approach was made over the second metacarpal. The tumor did not invade the surrounding soft tissues. The distal portion of the second metacarpal was removed (about 75\% of its totality) [Fig.4]. A direct lateral approach was made on the ipsilateral fibula and a free graft that measured 5 centimeters was harvested. The graft was shaped in order to simulate the metacarpal head, the distal cartilage of the removed metacarpal was removed and applied to the distal portion of the fibular graft in order to make the metacarpo-phalangeal joint more functional. The graft was fixed to the proximal portion of the second metacarpal with a plate and screws. There were no intra-operative complications. The pathological exam confirmed the diagnosis of bone giant cell tumor [Fig.5,6]. The patient was allowed passive mobilization of the fingers and wrist on the $5^{\text {th }}$ post-operative day and active movement on the $10^{\text {th }}$ post-operative day.

At three years of follow-up, there is good integration of the graft and no recurrence [Fig.7,8]. The patient has good overall hand function with

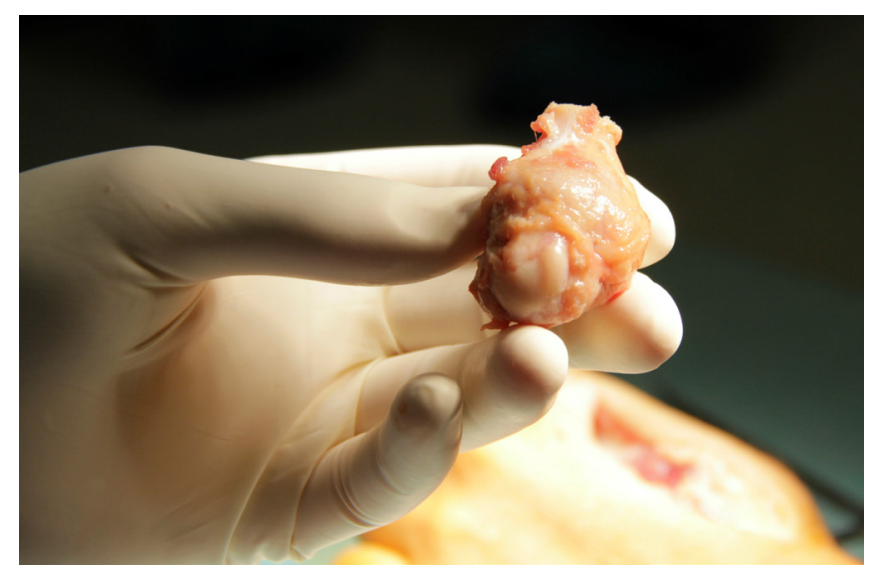

Fig.4: Mass after excision.
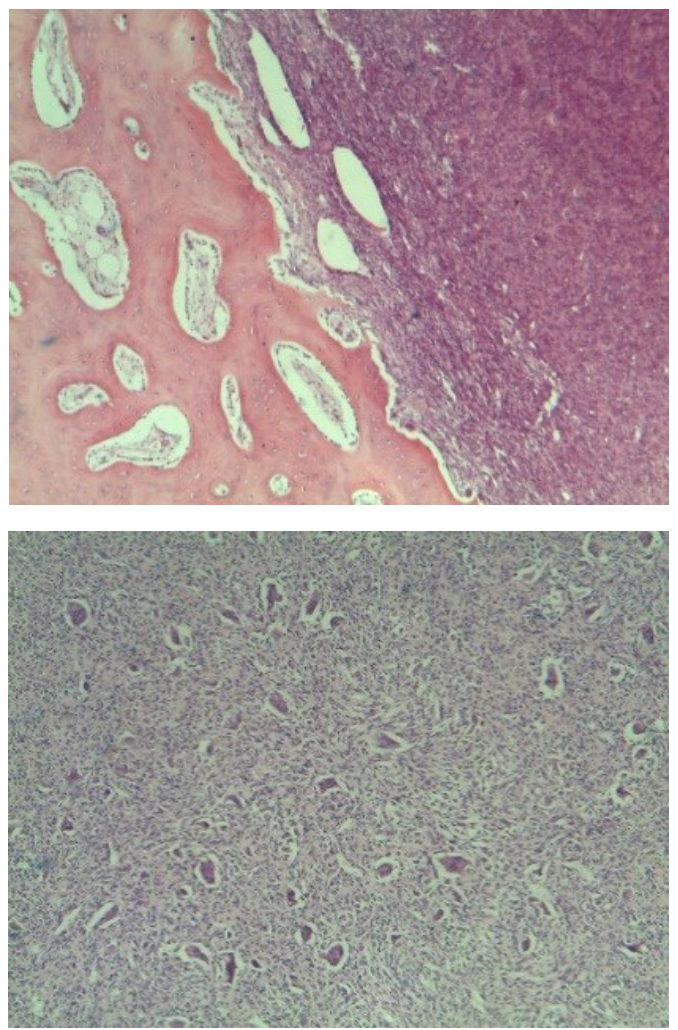

Fig.5,6: Pathological examination showing giant cell tumor of bone.

low pain (VAS 1 ) in the $2^{\text {nd }}$ metacarpal-phalangeal joint. The range of movement of the second metacarpal-phalangeal joint is $0^{\circ} / 30^{\circ}$ extension/ flexion. The patient returned to his previous occupation without limitations [Fig.9,10]. 

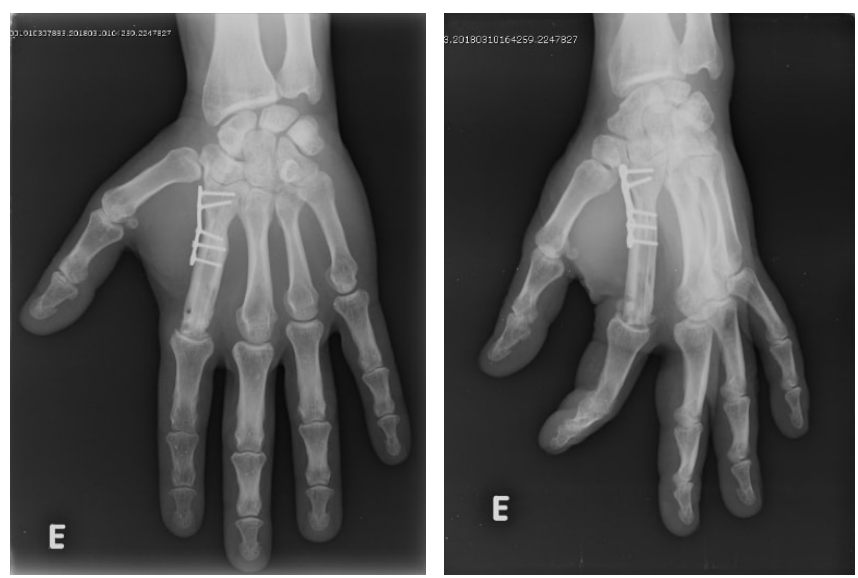

Fig.7,8: AP and lateral X-ray view at 3 years follow-up.

\section{Discussion}

In these tumors, given their locally aggressive characteristics, complete surgical excision is recommended. Cases of dissemination at a distance have been described, with special incidence at the pulmonary level. Although these metastases are usually benign, a follow-up of at least three years is recommended [6]. Recurrence rates of upto $10 \%$ are described in ray amputation [7], but the resulting morbidity is something that weighs heavily on the patient's decision. This option was initially suggested but was refused by the patient.

Reviewing the literature, and especially considering the first ray, the are several accounts of techniques that involve resection and reconstruction with autologous graft from the fibula, iliac crest or metatarsals [2,6]. Regarding the metacarpophalangeal joint, arthrodesis and the use of silicone prostheses have been described, but especially in young and active patients, these options do not yield in most cases, a good functional result $[3,6]$.

The use of free or vascularized fibular grafts is widely described in traumatology and oncology. Vascularized grafts are technically more difficult but tend to present lower rates of nonunion. The free graft union rates are as high as $89 \%$ $[8,9]$. Possible complications are delayed union or nonunion, stress fractures and infection. The
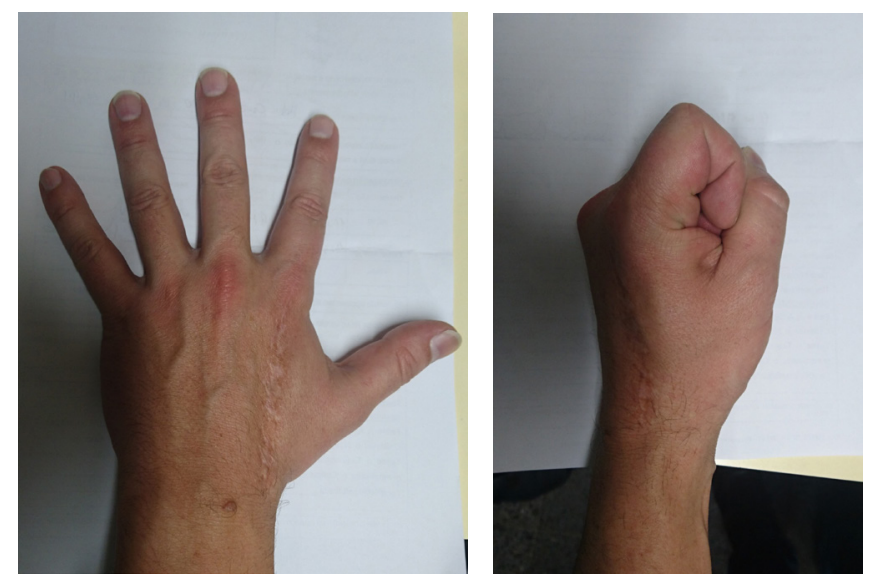

Fig.9,10: AP and lateral hand view.

authors did not find in the literature descriptions of cartilage transplantation in cases such as this, for the reconstruction of the proximal part of the metacarpal-phalangeal joint. However, this was attempted with some success, since there is maintenance of part of the joint space and the absence of degenerative changes on the phalanx side.

With three years of follow-up the patient is satisfied, with a globally conserved function, absence of recurrence and complete consolidation, there were also no complications at the site the of fibula graft.

\section{Conclusion}

The free fibular graft is a possible solution to avoid ray amputation in cases of bone tumors in the metacarpals. Further studies are warranted to understand the use of cartilage transplantation in these cases.

Contributors: HF: manuscript writing, patient management; MC, RL, JS, ER, LF: manuscript editing, patient management. HF will act as guarantor. All authors approved the final version of this manuscript.

Funding: None; Competing interests: None stated.

\section{References}

1. Sobti A, Agrawal P, Agarwala S, Agarwal M. Giant cell tumor of bone - An overview. Archives of Bone and Joint Surgery. 2016;4(1):2-9. 
2. Jones N, Dickinson B, Hansen S. Reconstruction of an entire metacarpal and metacarpophalangeal joint using a fibular osteocutaneous free flap and silicone arthroplasty. J Hand Surg Am. 2012;37:310-315.

3. Lim S, Babineaux K. Reconstruction of an entire thumb metacarpal: A case report. Plastic and Reconstructive Surgery Global Open. 2016;4(2):e610.

4. Blackley H, Wunder J, Davis AM, White LM, Kandel $\mathrm{R}$, Bell RS. Treatment of giant-cell tumors of long bones with curettage and bone grafting. J Bone Joint Surg Am. 1999;81:811-820.

5. Averill R, Smith R, Campbell C. Giant-cell tumors of the bones of the hand. J Hand Surg Am. 1980;5:39-50.

6. Naam NH, Jones SL, Floyd J. Multicentric giant cell tumor of the fourth and fifth metacarpals with lung metastases. Hand (N Y). 2014;9:389-392.

7. Oliveira V, van der Heijden L, van der Geest IC, Campanacci DA, Gibbons CL, van de Sande MA, et al. Giant cell tumours of the small bones of the hands and feet: long-term results of 30 patients and a systematic literature review. Bone Joint J. 2013;95-B:838-845.

8. Kotwal P, Nagaraj C, Gupta V. Vascularised joint transfer in the management of recurrent giant cell tumour or the second metacarpal. J Hand Surg Eur. 2008;33:314-316.

9. Maini L, Cheema G, Yuvarajan P, Gautam V. Free osteoarticular metatarsal transfer for giant cell tumor of metacarpal - a surgical technique. J Hand Microsurg. 2011;3:89-92. 